\title{
Evaluation of Formal Method Usage amongst Babcock University Students in Nigeria
}

\author{
F. A. Kasali \\ Department of Computer \\ Science, Babcock University \\ O. Ebiesuwa \\ Department of Computer Science, Babcock \\ University
}

\author{
Y. A. Adekunle \\ Department of Computer \\ Science, Babcock University
}

\author{
A. A. Izang \\ Department of Computer \\ Science, Babcock University
}

\author{
O. Otusile \\ Department of Computer Science, Babcock \\ University
}

\begin{abstract}
The knowledge of Formal Methods involves techniques and tools that are based on mathematics but most students tend to have poor approach in applying these techniques during software systems developmental processes despite all the potentials that using formal methods possess in designing systems that are error free, robust and more reliable. This study was conducted to evaluate formal methods usability among students and to enable them understand how important it is to embrace this technique in building highly reliable systems and for the academia to work more on bridging the gap between research and industries so as to promote the use of formal methods in software engineering companies.

In this paper, the benefits that Formal Methods has to offer in the area of Software Development was explored including present challenges affecting their usability, the present level of awareness and usage amongst students of computer science who have acute interest in software engineering was also evaluated.
\end{abstract}

The research was done quantitatively using a pilot study of students selected conveniently from Babcock University, Ilisan, Nigeria Computer Science students. A usability evaluation model was used in designing the measuring tool focusing on awareness, learnability, ease of use and willingness to use formal methods in their Research works and they were evaluated using descriptive statistical method. The measuring tool was analyzed using Statistical Package for Social Sciences (SPSS) version 21.0. Reliability test was done and found to be 0.906 which indicated a high internal consistency. The result of the analysis shows that if formal methods is easy to learn, then students will find it easy to use and the willingness to use it for their projects will be there. If they are willing to use it, then learnability and ease of use will also be high. Conclusion and Recommendations were also given at the end of the Research analysis.

\section{Keywords}

Formal Methods, Software Development, Usability, Software Systems

\section{INTRODUCTION}

Formal Methods (FM) refer to a variety of mathematical modeling techniques that are used to model the behavior of a computer system and to verify that the system satisfies design, safety and functional properties [1]. As a result of the benefits that the use of FM promises, scientific societies such as
Institute of Electrical and Electronics Engineers (IEEE), Association for Computing Machinery (ACM) amongst others describe it as one of the technique that an aspiring Software Engineer should be aware of [2]. Using mathematical model in software systems is important especially with systems that need to be highly reliable.

More recently, using FM comes highly recommended by the official norms adopted in the design of critical software [3]. The roles that the knowledge of FM play in software developmental processes is so important that nearly all computer science students in tertiary institutions all over the world are mandated to take this subject [4] but in contrast few students really make use of the knowledge when it comes to actual system design especially in designing safety and business critical systems. It is a known fact that the software industry continues to grow at a geometrical rate and this growth also includes the various functions that software provides hence, making them to become more complicated as people's needs continually grow. As a result, the probability that negligible errors will keep occurring increases which may cause devastating financial loss, time or even human life in severe cases [5]. In more developed countries, their seriousness about using FM in software development is so much that there exist bodies and societies that support the use of FM for computer system development such as Formal Methods Europe [6].

Gibson [7] in his conference paper ascertained that most computer science students do not appreciate the benefits that using FM are to software development. He opined that the major limitation why students feel reluctant in studying and applying the course is due to lack of motivation. He said "how can students be expected to eagerly accept a challenging course when the learning benefits aside to pass exams are not clear". Despite the many promises that FM has to offer, it is a road that is less travelled by student developers as most believe that FM techniques are hard to master, tedious to use and not well suited for projects that need to be submitted within a short time frame [8]. To build reliable, safety-critical and ever increasing complex systems, teaching formal methods theoretically is not just enough but students need to understand and appreciate the benefits that this abstract modelling technique has to offer to increase its usage amongst them. 


\subsection{Motivation for this Research}

The main reason why this research was conducted was majorly because the Researchers realized that despite the benefits that using Formal Methods promise in building highly reliable and quality systems, most students in their Institution do not use it as a form of Verification or Validation method as a result of one reason or the other. The Researchers tried to declaim this point by going through all the projects that students have been doing in the Computer Science department of Babcock University since its inception and not just one Research project, dissertation nor thesis that Formal Methods is used was found as most students rather prefer to use black box testing and other software testing methods despite the fact that Formal Methods as a course is being taught very well by able lecturers and some of this students perform well in it in class.

\subsection{Research Questions}

1. What are the factors that normally discourage students from using FM during the course of their project?

2. Do Computer Science students find learning FM easy?

\section{LITERATURE REVIEW}

\subsection{Uses of Formal Methods}

Formal methods are basically used for systems specification and two types of verification namely model checking (requirements validation) and theorem proving (program proving). They are mostly used for safety critical systems, high financial risk systems and almost anywhere that high quality software systems are needed. Its activities include writing a specification using a formal notation, validating the specification and then inspecting it with domain experts. Other important use of formal methods is in modeling and analyzing requirements interaction [9]. The history of formal methods dates back to 40 years, yet students still wonder how this method is applied in Computer Science especially in the area of Software engineering and at what stage of development lifecycle. As a result and despite its significant demonstrated benefits, formal methods remain poorly accepted by industrial practitioners because of numerous claims ranging from difficult mathematical techniques, inadequate tools in existence, they could cause delay and at times are incompatible with other software packages. For years, academics claim that the use of formal methods in software development would lead to better software process and increased software quality but there exist a general lack of acceptance of formal methods [10]. A major goal of software engineering is to enable developers to construct systems that operate reliably despite the complexity. One way of achieving this goal is by using formal methods, which are mathematically based languages, techniques and tools for specifying and verifying such systems although using formal methods does not guarantee absolute correctness. However, they can greatly increase our understanding of a system by revealing inconsistencies, ambiguities and incompleteness that could have otherwise gone undetected [5].

\subsection{Recent Applications of Formal Methods}

Since 2011, engineers at Amazon Web Services (AWS) have used formal and model specification to help solve difficult design problem in critical systems. They used formal methods to find bugs in system designs that cannot be found through any other technique and they realized that using formal methods are surprisingly feasible for mainstream software development and gives good return on investment. At amazon, formal methods are routinely applied to the design of complex real world software, including public cloud service. It has also helped them to devise aggressive optimizations to complex algorithms without sacrificing quality [11].

Faheem, Farooq, Nabal and Nazir [12] designed a verifiable and reusable data access layer using formal methods and design patterns. They applied formal methods to the data access layer which resulted in a more verifiable recipes for solving data access layer design problems. They described the formal method using VDM+++ (Extension of the Vienna Development Method) specification language that was developed at International Business Machine (IBM) Vienna laboratory and which supports the modeling of object oriented and concurrent systems, analyzed and validated the system using the VDM+++ Toolbox.

In a research paper, Nassima, Olivier, Marc and Xavier in 2010 [12] addressed the issue of the development of correctby-construction components for GeneAuto, a qualifiable automatic code generator that transforms Simulink, State flow and Scicos models to MISRA C code for safety critical system. The approach combined classical development process, formal specification and verification using proof assistants and eventually derived formal specifications from classical user and tools requirement, formally implemented and verified the correctness of some components of the code generator. They applied this study to real size industrial use cases from various transportation domain partners and led to requirement errors detection and a correct-by-construction implementation with reduction of test effort.

Lichen, Jifeng and Wensheng in 2013 [14] used differential dynamic logic (DL) to specify cyber physical systems and generated test cases from formal specifications into the models of Modelica which is a new language for hierarchical object oriented physical modeling that was developed through international efforts. They finally tested the cyber physical systems using simulation techniques and concluded that they were able to address the problem of generating test cases from cyber physical systems from formal specifications and reduced an infinite set of testing parameters into a finite set.

Mohammed, Nazir, Mohammed, Sana and Mahmoud in 2014 [15] designed a localized algorithm for segregation of critical/non critical nodes (LASCNN) to the network connectivity. They designed this algorithm to establish and maintain k-hop connection list and marks a node as critical if its k-hop neighbors become disconnected without the node and non-critical otherwise. They used both formal and nonformal techniques for verification and validation of functional and non-functional properties. They transformed LASCNN to formal specification using $\mathrm{Z}$ notation. After analyzing and validating it, they now simulated LASCNN specification to quantitatively demonstrate its efficiency. The simulation experiment demonstrated that the performance of LASCNN was scalable and quite competitive compared to other schemes.

All these applications are just but a few uses of formal methods in designing highly reliable systems but despite all its benefits, using formal methods by developers is still a 
challenging issue based on some limitations as highlighted by [16] in an online article:

- Using formal method models can be time consuming and expensive

- Formal methods techniques and models are difficult to use as a communication mechanism for no technical personnel

- Extensive training is required in using formal methods since only few developers have the essential knowledge to implement these models.

Formal methods for software engineering have been available for more than a decade, few have had significant impact in practice because software developers find formal methods difficult to use and apply. Some researchers also claim that a complete formal verification of a large complex system is not practical but they can still be applied to various aspects of large or small, safety-critical systems. There also exist the issue of creativity since formal methods are strictly descriptive and analytical in nature. Formal methods deal with software itself and its documentation ignoring other important components of software products such as training, customer support amongst others thereby not really contributing to the entire software product quality. Most software systems normally take inputs from external environment which may not be predictable. This sort of issue usually create the problem of developing correct specifications and deciding what behavior is correct [17].

\subsection{Teaching Formal Methods}

During the second International Conference held in Netherlands in 2009, Jeremy and Juse Nuno [18] summarized the experiences they encountered in teaching formal methods to their students by helping them to build skills on formal methods, to master formal tools that will be useful to them in future endeavors. They felt the students themselves have had enough software engineering and mathematical background to appreciate the benefits of using formal methods tools and techniques during software development. At the end of the day, they evaluated student's attitude towards the course and realized that student's attendance was very low. They identified two main causes for student's lack of interest towards the course:

- The usefulness of formal methods in industrial software development is not obvious to the students. They really do not see the benefit of formal verification and analysis, also, formal methods are rarely used in software companies, and hence, the students are not compelled to learn about them.

- Courses on formal methods typically require significant mathematical background and they are also typically more demanding than other courses. Since most students prefer to choose the easier way to get the degree, they tend to avoid mathematics as much as possible.

\section{METHODOLOGY}

In designing the measuring tool, four aspects of Usability that was focused on include; Awareness, Learnability, Ease of Use and Willingness to use Formal Methods by the respondents. To evaluate students' usage of Formal Methods in their Projects, quantitative research in the form of questionnaire survey was conducted to meet the goals of the research. The use of questionnaires allowed the researcher to have more control over how the information was collected and decide on some requirements such as size of the project, time frame and goal. The measuring scales were developed using psychometric scales and the variables consisted of Likert's scale. The reliability of the measuring instrument was done using Cronbach's alpha reliability coefficient for Likert-type scales was used to ascertain the reliability of the measuring instrument and to verify the validity of the instrument, five quantitative techniques experts were used in authenticating and confirming the measuring tool developed. Statistical Software Package (SPSS version 21.0) was used to evaluate the data gotten from the respondents.

\subsection{Sample Size and Sampling Technique}

The data used in evaluating Formal Methods usage was obtained from the Computer Science department of Babcock University, Ilisan Remo Ogun State, a leading and foremost Private Christian University in Nigeria. Convenience sampling which is a non- probability sampling technique was used because of the Institution's accessibility and proximity to the Researchers. Random sampling which is a probabilistic method of sampling was now used in the selection of respondents. The total population of the students in Computer Science Department both at the Undergraduate and Postgraduate level was determined to know the total number of people who are to be in the group that the sample represented. The sample size was determined using a sample size calculator that was designed by Creative Research Systems survey software for its accuracy.

\subsection{Data Presentation}

The total population of the number of Computer Science students both at the undergraduate and postgraduate level was found out to be around 1500 from the departmental secretary. The sample size was gotten by using the sample size calculator developed by Creative Research Systems and after calculation, the sample size was gotten to be 150 based on a confidence level of $95 \%$ as mostly used by researchers, confidence interval of 7.59 and a sampling frame of 1500 which is also the total population size. By putting the confidence level and confidence interval together, then, we can say that we are $95 \%$ sure that the true percentage of the population lies between a certain confidence interval

The sample of survey was basically Computer Science students, the total population of Computer Science students both at the Undergraduate and Post graduate level are about for example $37.4 \%$ of the sample surveyed say they find it easy to learn formal methods concepts and tools which means that with a confidence interval of 7.59 , this implies that between $29.81 \%$ and $44.99 \%$ of the entire population find it easy to learn formal methods concepts and tools which is not even up to half of the entire population surveyed. The measuring tool consists of 2 parts namely Section A and Section B. Section A deals with the demographic profile of students and Section B includes a five point Likert scale items with response ranging from five to one representing Strongly Agree (5), Agree (4), Undecided (3), Disagree (2) and Strongly Disagree (1) in getting to know the Awareness of Formal Methods amongst students, its Learnability, Ease of use and Remembering Formal Methods and their willingness to use Formal Methods. The Cronbach's alpha value for the tool was evaluated to be 0.906 which depicts the tool as a very 
reliable one. 150 questionnaires were administered and 131 was returned which yields a response rate of $87.3 \%$.

Table 1. Case Processing Summary

\begin{tabular}{|ll|r|r|}
\hline & & $\mathrm{N}$ & \multicolumn{1}{|c|}{$\%$} \\
\hline \multirow{3}{*}{ Cases } & Valid & 129 & 98.5 \\
& Excluded $^{\mathrm{a}}$ & 2 & 1.5 \\
& Total & 131 & 100.0 \\
\hline
\end{tabular}

a. Listwise deletion based on all variables in the procedure.

Table 2. Reliability Statistics for measuring tool

\begin{tabular}{|r|r|}
\hline Cronbach's Alpha & N of Items \\
\hline .906 & 29 \\
\hline
\end{tabular}

\subsection{Discussion and Analysis of Findings}

From the findings, it was evident that most of the respondents were male students with a total of 67 representing $51.1 \%$ of the total population as depicted in Table 3

Table 3. Sex of respondents

\begin{tabular}{|r|r|r|r|r|}
\hline & Frequency & Percent & \multicolumn{1}{|c|}{$\begin{array}{c}\text { Valid } \\
\text { Percent }\end{array}$} & $\begin{array}{l}\text { Cumulative } \\
\text { Percent }\end{array}$ \\
\hline Fem & 64 & 48.9 & 48.9 & 48.9 \\
ale & & & & \\
Valid & & 51.1 & 51.1 & 100.0 \\
Male & 131 & 100.0 & 100.0 & \\
\hline
\end{tabular}

Table 4. Age of respondents

\begin{tabular}{|r|r|r|r|r|}
\hline & Frequency & Percent & \multicolumn{1}{|c|}{$\begin{array}{c}\text { Valid } \\
\text { Percent }\end{array}$} & $\begin{array}{c}\text { Cumulative } \\
\text { Percent }\end{array}$ \\
\hline Below & 38 & 29.0 & 29.0 & 29.0 \\
20 & & & & \\
Valid 20-25 & 81 & 61.8 & 61.8 & 90.8 \\
$26-30$ & 12 & 9.2 & 9.2 & 100.0 \\
Total & 131 & 100.0 & 100.0 & \\
\hline
\end{tabular}

Table 5. Level of respondent

\begin{tabular}{|c|r|r|r|r|}
\hline & $\begin{array}{r}\text { Frequenc } \\
\mathbf{y}\end{array}$ & Percent & $\begin{array}{c}\text { Valid } \\
\text { Percent }\end{array}$ & $\begin{array}{c}\text { Cumulative } \\
\text { Percent }\end{array}$ \\
\hline 200 & 8 & 6.1 & 6.1 & 6.1 \\
300 & 24 & 18.3 & 18.3 & 24.4 \\
Valid 400 & 89 & 67.9 & 67.9 & 92.4 \\
Others & 10 & 7.6 & 7.6 & 100.0 \\
Total & 131 & 100.0 & 100.0 & \\
\hline
\end{tabular}

A larger percentage of the respondents (42.7\%) agreed to have been taught formal methods before and also claimed that the lecturers did a good job in teaching them its basic principles, concepts, applications and benefits which means that they are fully aware of formal methods importance in building reliable critical systems but the nagging question is why they do not use for their research projects because the project library was explored and it was found out that no single Computer Science student in Babcock University both at the undergraduate and Postgraduate level have ever used Formal Methods in any of their project or other research studies. From the analysis of the measuring tool, about $68.8 \%$ of the population of students surveyed claimed that using formal methods techniques in projects is time consuming, expensive and most of them are not really exposed to using formal methods tools, techniques and some of the programming languages as it also require lots of advanced mathematics and too complex in nature, hence all these factors discourage most of them from attempting to use it.

\subsection{Descriptive Statistics for the measurement items}

For the twenty three items, descriptive statistics were investigated including mean, standard deviation, skewness, and kurtosis. Table 6 presents the descriptive statistics for sampled students' responses. Overall, a mean value of responses of all 23 items was 3.47, and the standard deviation was 0.99 . When investigating by subscale, the Awareness subscale items showed relatively higher means than the others. The data achieved a normal distribution with skewness and kurtosis values between -1 and 1 . In terms of skewness, all the items turned out negatively distributed as the mean values were higher than four. For kurtosis, most items showed negative. Although the overall data showed negative skewness, the distribution was close to normal distribution, which reveals the measurement items are appropriate to discriminate the differences of measurement in each construct. This present study is consistent with the study findings of Soohyung, Suyu and Kun [19] who proposed their own Usability model for Academic Library websites using Efficiency, Effectiveness and Learnability as the metrics of Usability Evaluation but for this Research purpose, Awareness level of Formal Methods Usage, Learnability, Ease of Use and Remembering Formal Methods and Willingness to use Formal Methods were used as the Usability metrics in other to achieve the objectives of the Research. Karima, Ali and Alain [20] also presented an empirical study using some set of measures to evaluate mobile application usability. In their study, 32 users participated in the experiment and after analysis of the measuring instrument that was developed based on ISO 25062 and ISO 9421 standards using SPSS under Microsoft environment, the result of the experiment was analyzed using descriptive statistics but more users should have been used to give a better representation of the actual population. The basic idea about Usability is the ease of use and learnability of human made objects as is usually being depicted in most Usability models and standards as shown in Figure 1 and this could be a book, tool, software applications, technique or any other thing that a human can relate with. Most Research on Usability is usually focused on an already developed Software of Hardware applications but usually not on the techniques, process or methods that are required by students and developers at large in ensuring that these systems are effectively and reliably developed. 


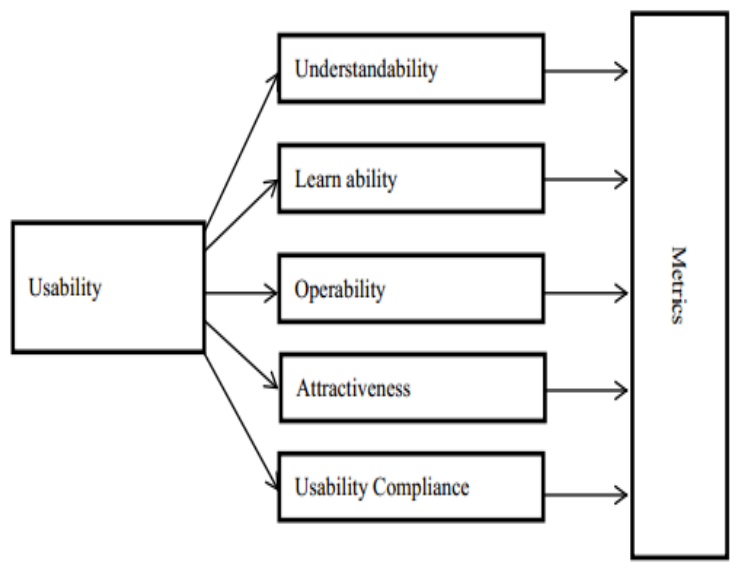

Fig. 1. ISO-9126 Standard [21]

Table 6: Descriptive Statistics of responses for the measured items

\begin{tabular}{|l|l|l|l|l|}
\hline Item & Mean & $\begin{array}{l}\text { Standard } \\
\text { deviation }\end{array}$ & Skewness & Kurtosis \\
\hline AW1 & 3.64 & 1.151 & -0.921 & 0.702 \\
\hline AW2 & 3.46 & 1.090 & -0.741 & 0.904 \\
\hline AW3 & 3.37 & 0.986 & -0.500 & 0.080 \\
\hline AW4 & 3.50 & 0.915 & -0.624 & 0.327 \\
\hline AW5 & 3.56 & 0.938 & -0.822 & 0.584 \\
\hline LA1 & 3.46 & 0.947 & -0.430 & 0.230 \\
\hline LA2 & 3.36 & 1.001 & -0.352 & 0.025 \\
\hline LA3 & 3.32 & 0.987 & -0.439 & -0.028 \\
\hline LA4 & 3.53 & 0.844 & -0.552 & 0.646 \\
\hline LA5 & 3.50 & 0.956 & -0.521 & 0.020 \\
\hline EURFM1 & 3.27 & 0.938 & -0.399 & 0.334 \\
\hline EURFM2 & 3.34 & 0.945 & -0.732 & 0.806 \\
\hline EURFM3 & 3.37 & 0.979 & -0.364 & 0.234 \\
\hline EURFM4 & 3.25 & 0.986 & -0.450 & 0.309 \\
\hline EURFM5 & 3.33 & 1.084 & -0.503 & -0.446 \\
\hline EURFM6 & 3.14 & 1.036 & -0.314 & -0.419 \\
\hline WFM1 & 3.35 & 1.058 & -0.749 & 0.121 \\
\hline WFM2 & 3.21 & 1.014 & -0.602 & 0.032 \\
\hline WFM3 & 3.22 & 1.090 & -0.634 & 0.038 \\
\hline WFM4 & 3.15 & 0.901 & -0.643 & 0.380 \\
\hline WFM5 & 3.24 & 0.923 & -0.676 & 0.840 \\
\hline WFM6 & 3.17 & 1.004 & -0.609 & 0.333 \\
\hline WFM7 & 3.16 & 0.950 & -0.702 & 0.691 \\
\hline AW-Awad & & LA-Lea \\
\hline
\end{tabular}

AW-Awareness LA-Learnability

EURFM- Ease of Use and Remembering Formal Methods

WFM-Willingness to use Formal Methods
Correlation between AW, LA, EURFM and WFM

Table 7: Correlation between Usability Metrics used

\begin{tabular}{|c|c|c|c|c|c|}
\hline & & $\begin{array}{c}\text { Awaren } \\
\text { ess } \\
\text { Average }\end{array}$ & $\begin{array}{c}\text { Learna } \\
\text { bility } \\
\text { Averag } \\
\text { e }\end{array}$ & $\begin{array}{c}\text { Ease of } \\
\text { Use } \\
\text { average }\end{array}$ & $\begin{array}{c}\text { Willing } \\
\text { ness } \\
\text { average }\end{array}$ \\
\hline \multirow{4}{*}{$\begin{array}{l}\text { Awareness } \\
\text { Average }\end{array}$} & $\begin{array}{l}\text { Pearson } \\
\text { Correlation }\end{array}$ & 1 & $.771^{* * *}$ & $.566^{* * *}$ & $.565^{* *}$ \\
\hline & $\begin{array}{l}\text { Sig. (2- } \\
\text { tailed) }\end{array}$ & & .000 & .000 & .000 \\
\hline & $\mathrm{N}$ & 131 & 131 & 131 & 131 \\
\hline & $\begin{array}{l}\text { Pearson } \\
\text { Correlation }\end{array}$ & $.771^{* *}$ & 1 & $.784^{* *}$ & $.711^{* *}$ \\
\hline \multirow[t]{3}{*}{$\begin{array}{l}\text { Learnability } \\
\text { Average }\end{array}$} & $\begin{array}{l}\text { Sig. (2- } \\
\text { tailed) }\end{array}$ & .000. & & $\begin{array}{l}0 \\
0 \\
0\end{array}$ & .000 \\
\hline & $\mathrm{N}$ & 131 & 131 & 131 & 131 \\
\hline & $\begin{array}{l}\text { Pearson } \\
\text { Correlation }\end{array}$ & $.566^{* *}$ & $.784^{* * *}$ & 1 & $.777^{* * *}$ \\
\hline \multirow[t]{3}{*}{$\begin{array}{l}\text { Ease of Use } \\
\text { average }\end{array}$} & $\begin{array}{l}\text { Sig. (2- } \\
\text { tailed) }\end{array}$ & .000 & .000 & & .000 \\
\hline & $\mathrm{N}$ & 131 & 131 & 131 & 131 \\
\hline & $\begin{array}{l}\text { Pearson } \\
\text { Correlation }\end{array}$ & $.565^{* *}$ & $.711^{* *}$ & $.777^{* *}$ & 1 \\
\hline \multirow[t]{2}{*}{$\begin{array}{l}\text { Willingness } \\
\text { average }\end{array}$} & $\begin{array}{l}\text { Sig. (2- } \\
\text { tailed) }\end{array}$ & .000 & .000 & .000 & \\
\hline & $\mathrm{N}$ & 131 & 131 & 131 & 131 \\
\hline
\end{tabular}

**. Correlation is significant at the 0.01 level (2-tailed).

From Table 7, it can be seen that there is high association between Awareness level of using Formal Methods among students and Learnability but an average relationship exist between Learnability, Ease of use and willingness to use formal methods. If formal methods is easy to learn, then students will find it easy to use and the willingness to use it for their projects will be there. If they are willing to use it, then learnability and ease of use will also be high as seen in the table.

\section{RECOMMENDATIONS AND CONCLUSION}

The most important goal of formal methods is to help developers build highly reliable systems hence it cuts across all computer science areas. Its origin lies basically in mathematics, its intended applications are hardware and software systems and its potential users are all developers involved in system engineering processes. As technology grows continually, it becomes viable to attack larger and more complicated problems. For increased formal methods usage in industries, more critical researches should be done, fresh ideas are needed to reduce the mathematical complexity, better and more user friendly tools should be developed that can integrate different methods to work together intensive efforts should be made by researchers to work with practitioners to enable effective transfer of technology.

In schools, teachers should not just assume that students have the basic requirements to learn, appreciate and use formal methods, they should ask important questions, assess them regularly not just with assignments but evaluate them psychologically by introducing them to both the practical and 
theoretical aspects. The present problem here is on the proper way to train students on the use of formal methods, how to educate industry and society to use the trained people effectively. Students should be encouraged to use Formal Methods techniques in their projects by getting enough assistance from their Project supervisors, given more time frame for the successful completion of their projects and they should be given moral and financial incentives when building critical systems by their department and the Institution at large.

Teachers, Researchers and other stakeholders need to ascertain and know if formal method education is worth the effort in this country and if that is done also know how to teach industry on the proper roles for software development using formal methods, how to convince professional bodies of the proper place of formal methods in our profession and lastly, how to get the numerous Institutions in the country to teach mathematics as the basis of all software engineering activities.

\section{REFERENCES}

[1] Sotiriadou, A., \& Kefalis, P (1999). Teaching Formal Methods in Computer Science Undergraduates, Retrieved from www.city.academic.gr/special/research/Xcityng/pa

[2] Tucker, A. (1996). Computing Curricula; Report of the ACM/IEEE Computer Science Joint Curricular Task Force

[3] Almeida, J. B., Frade, M. J., Pinto, J. S., Melode, S. (2011). Rigorous Software Development; An introduction to Program Verification, ISBN 978-085729-018-2, Pg. 15-44, Retrieved from springer.com/us/book/9780857290182

[4] Collin, J.B. (1996). The role of formal methods in Software Engineering Education and Industry, Retrieved from researchgate.net/publication/228701451

[5] Edmund, M. C., Jeannette, M.W. et al., (1996). Formal Methods; State of the Art and Future Directions, ACM Computing Surveys, Vol. 28, Issue 4, Pg. 623-626

[6] Formal Methods Europe (2015). A guide to FME Sponsorship Version 2.2. Retrieved from www.fmeurope,org/wp-content/uploads/2015

[7] Gibson, J. P. (2008). Weaving a Formal Methods Education with Problem based learning, Conference Paper DOI: 10.1007/978-3-540-88479-8_32, Pg. 460472, Retrieved from www.researchgate.net

[8] John, A. (2010). Formal Methods in Software Development: A road less travelled, South African Computer Journal, No 45, Pg. 40

[9] Phillip, A. L. (2014). Requirements Engineering for Software and Systems, Second Edition, Retrieved from https://books.google.com.ng/

[10] John, C. K., Collen, L. D., Mathew, S. G., Luis, G. N. (1997). Why are formal methods not used more widely?
Retrieved

from www.cs.virginia.edu/jck/publicationd/Ifm.97.pdf

[11] Chris, N., Tim, R., Fan, Z., Bogdan, M., Marc, B., Micheal, D. (2015). How Amazon Web Services Uses Formal Methods, Communications of the ACM, Vol. 58, No. 4, Pages 66-73

[12] Faheem, S., Farooq, Z., Nabal, S., Nazir, A. Z., (2009). Designing Verifiable and Reusable data access layer using Formal Methods and Design Patterns, International Conference on Computer Modeling and Simulation, Pg. 167-172, doi 10.1109/iccms.2009.83

[13] Nassima, I., Olivier, S. Y. K., Marc, P., Xavier, T. (2010). Use of Formal Methods for Building Qualified Code Generator for Safer Automotive Systems, ACM digital library, ISBN: 978-1-60558-915-2

[14] Lichen, Z., Jifeng, H., Wensheng, Y. (2013). Test Case Generating From Formal Methods of Cyber Physical Systems, International Journal of Hybrid Information Technology, Vol. 6, No. 3

[15] Mohammed, A., Nazir, A. Z., Mohammed, I., Sana, U., Mahmoud, F. (2014). Formal Specification and Validation of a Localized Algorithm for Segregation of Critical/Non-Critical Nodes in MAHSNs. International Journal of Distributed Sensor Networks, Article ID 140973, http://dx.doi.org/10.1155/2014/140973

[16] Dinesh, T. (2015). What is Formal Methods, Advantages and Disadvantages? Retrieved from ecomputers.com/software-engineering/formal-methodsmodel

[17] Mona, B., Amit, M., Meenu, D. (2013). Formal Methods: Benefits, Challenges and Future Direction, Journal of Global Research in Computer Science, Vol. 4, No. 5 ISSN-2229-371X, Available Online at www.jgrcs.info

[18] Jeremy, G., Jose Nuno, O. (2009): Teaching Formal Methods; Second International Conference, TFM Proceedings, ISSN: 03029743, Retrieved from https://books.google.com.ng/books?id=kydqCQAAQBA $\mathrm{J} \&$ printsec $=$ frontcover $\# \mathrm{v}=$ onepage $\& \mathrm{q} \& \mathrm{f}=$ false

[19] Soohyung, J., Suyu, L., \& Kun, L. (2011). A Usability Evaluation Model for Academic Library Websites: Efficiency, Effectiveness and Learnability, Journal of Library and Information Studies, Vol. 9, Issue 2, Pg. 1126

[20] Karima, M., Ali, I., \& Alain, A. (2016). Usability evaluation of mobile applications using ISO 9241 and ISO 25062 standards. SpringerPlus 5:548, DOI 10.1186/s40064-016-2171-z

[21] Esraa S., Noureldien, A. N. (2015). Usability Measurement Model (UMM): A New Model for Measuring Websites Usability, International Journal of Information Science 2015, Vol. 5, Issue 1, DOI: 10.5923/j.ijis.20150501.02, Pg. 5-13. 